\title{
CAROLINA MARIA DE JESUS: CONTRIBUIÇÕES DE UMA INTELECTUAL NEGRA
}

\author{
Fernanda de Souza Cardoso* \\ Não sou o objeto, mas o sujeito. Eu sou \\ quem descreve minha própria história, e não \\ quem é descrita. Escrever, portanto, emerge \\ como um ato político. \\ (Grada Kilomba)
}

\section{RESUMO}

Esse artigo é uma homenagem a Maria José Fontelas Rosado Nunes, a Zeca, a partir da apresentação de contribuições de mulheres pretas no protagonismo de suas próprias histórias, tendo Carolina Maria de Jesus como referência, visto que na intelectualidade de suas narrativas uniu dor e poesia. As histórias pessoais de Zeca e Carolina se diferenciam e há especificidades em suas identidades, mas ainda assim vários fios parecem aproximá-las: duas escritoras mineiras que se fazem cruciais nos embates travados cotidianamente contra muitos tipos de ódio e opressões contra a mulher, apontando sonhos, intenções e caminhos para a transformação dessa realidade. Palavras-chave: Mulheres, Negras, Intelectuais, Protagonismo.

\section{CAROLINA MARIA DE JESUS: CONTRIBUTIONS OF A BLACK INTEL- LECTUAL WOMAN}

\section{ABSTRACT}

This article is a tribute to Maria José Fontelas Rosado Nunes, Zeca, from the presentation of contributions by black women in the pro-

* Doutora em Ciências da Religião pela PUC-SP. Mestra em Educação Física pela Universidade Federal de Juiz de Fora. Graduada em Educação Física pela Universidade Estadual de Montes Claros. Professora do Departamento de Educação Física da Universidade Federal de Montes Claros, na área Corpo, Expressão e Movimento.

1 Recorte de citação de Grada Kilomba (2019, p. 28) retirado da Introdução do seu livro “Memórias da plantação: episódios de racismo cotidiano". 
tagonism of their own stories, with Carolina Maria de Jesus as a reference, since in the intellectuality of her narratives she connected pain and poetry. The personal stories of Zeca and Carolina differ and there are specificities in their identities, but still several threads seem to bring them together: two writers from Minas Gerais who make the crucial battles fought daily against many types of hatred and oppression against women, pointing at dreams, intentions and ways to transform this reality.

Keywords: Women, Black, Intellectuals, Protagonism.

\section{CAROLINA MARIA DE JESUS: CONTRIBUCIONES DE UN INTELEC- TUAL NEGRO}

\section{RESUMEN}

Este artículo es un homenaje a Maria José Fontelas Rosado Nunes, Zeca, de la presentación de contribuciones de mujeres negras en el protagonismo de sus propios cuentos, con Carolina María de Jesús como referencia, ya que en la intelectualidad de sus narrativas unió dolor y poesía. Los cuentos personales de Zeca y Carolina difieren y hay especificidades en sus identidades, pero aún así varios hilos parecen unirlas: dos escritores de Minas Gerais que juegan un papel crucial en los enfrentamientos librados diariamente contra muchos tipos de odio y opresión contra las mujeres, señalando sueños, intenciones y formas de transformar esta realidad.

Palabras-clave: Mujer, Negro, Intelectuales, Protagonismo.

\section{INTRODUÇÃO}

Neste artigo, presto minha homenagem a Maria José Nunes Rosado, a Zeca, pelos seus 75 anos de vida. Convivi com a Zeca entre 2012 a 2016, sendo sua orientanda de doutorado no Programa de Pós-Graduação em Ciências da Religião da PUC-SP. A Zeca marcou fortemente minha vida, meu modo de ver e de ser, especialmente ser mulher. Essas marcas se deram em função do que ela representa, em função de suas lutas, por si mesma e por todas nós: pelo nosso direito de decidir, falar, agir e protagonizar.

Eu, uma professora universitária da área de Educação Física, mineira como ela, oriunda do interior, especificamente do sertão do Norte de 
Minas Gerais, estava indo, como mulher negra, para onde queria em meu itinerário acadêmico: cursar doutorado na PUC-SP.

A possibilidade de cursar doutorado me trazia inquietações, a primeira era o fato de ter que descobrir uma cidade tão "imensa" como São Paulo - a "Paulicéia desvairada". A outra era o fato de que eu era a única da área de Educação Física do Programa e uma iniciante nos estudos da religião. Também houve certo receio, principalmente pelo fato de ser orientada por Zeca, uma mulher que eu só conhecia pelas prévias leituras que fiz sobre sua vida acadêmica e produções e da qual eu não tinha pleno conhecimento da sua importância para a ciência, para a sociedade, para nós mulheres.

Quando a conheci pessoalmente, em nossa primeira reunião de orientação na PUC, estava um tanto nervosa, pois a gente sempre tem aquele temor de não corresponder às expectativas de uma orientadora como a Zeca, com uma trajetória e grande reconhecimento acadêmico, social e político feminino.

A partir desse primeiro encontro de orientação, percebi que não se conhece alguém de fato somente pelo seu Currículo Lattes, pois Zeca foi extremamente gentil e sincera comigo. Eu estava nervosa, ela, com sua voz serena, falava baixo (o contrário de mim) e como mulher engajada na luta pela emancipação e conquista de direitos das mulheres, Zeca sempre transmitia um sentimento de confiança em mim (acho que até demais), e no que eu podia oferecer para construir a pesquisa e a tese de doutorado. Como exemplo disso, registro que nunca vou me esquecer do seu comentário sobre o meu objeto de estudo: a dança no candomblé. Ela humildemente disse: "eu não entendo nada de dança". E eu logo respondi: "e eu não entendo nada de religião"; e nós duas espontaneamente rimos. Percebemos ali o quanto poderíamos aprender juntas, certamente eu mais do que ela. Hoje dou-me conta de que seu gesto acolhedor encontra guarida na ideia de Paulo Freire (1987, p. 79) de que "ninguém educa ninguém, ninguém se educa a si mesmo", [as pessoas] se educam entre si, mediatizadas pelo mundo.

Em outra reunião de orientação, tive o privilégio de ser recebida em sua casa. Como uma boa anfitriã mineira, ofereceu-me um bom café. Sentadas à mesa tínhamos de um lado uma grande janela de vidro da 
qual podíamos avistar uma infinita Avenida Paulista (onde eu nunca havia pisado) e de outro lado uma admirável biblioteca. Fiquei imaginando quantos livros e conhecimentos estavam contidos ali. E neste nosso encontro mais uma vez fui surpreendida, pois em nossa conversa sobre a banca de defesa, Zeca enfatizou o quanto era importante que escoIhêssemos pessoas realmente dispostas a contribuir, a construir junto e não com a intenção de não colaborar ou de tentar ficar em evidência mais do que a própria pesquisa (algo bastante comum na fogueira das vaidades dos cenários acadêmicos). Novamente Zeca me deixou bastante segura e à vontade sobre esta questão. Saindo dali decidi caminhar pela Paulista, encantada com o tamanho de tudo e com a diversidade de cores, prédios e pessoas. Devo ter parado em mais de uma livraria pelo sentimento despertado em mim naquela visita: comprei livros e presentes para a família, quando na verdade estava eu me sentindo presenteada com tanto acolhimento, conhecimento e experiências compartilhadas! Zeca se fez presente!

Agora é nossa oportunidade de presenteá-la. É minha vez de tentar fazer-me presente em sua trajetória, objetivando nessas linhas apresentar e promover a presença de outra mulher que, a duras penas, buscou tornar-se o que queria! E minha escolha para homenagear a Zeca partiu da ideia de recorrer a Carolina Maria de Jesus, negra como eu e intelectual como ela. Mulher que como a Zeca me fez ver as coisas de forma diferente, mulher de resistência e insistência. Duas mulheres que lutaram para que o mundo se tornasse um lugar mais poético, menos desigual, mais acolhedor a todas e todos. Inspirada como mulher pelos discursos e contribuições da Zeca, é que fui conduzida a apresentar as contribuições de outras mulheres (que também me inspiram), tendo Carolina Maria de Jesus como referência. Por isso, esse texto objetiva também analisar como a luta da mulher negra se aglutina, mas também se diferencia ${ }^{2}$ da defesa da mulher, feita por Zeca.

É primordial que se faça aqui uma breve abordagem sobre em quê essa luta pelas causas da mulher se diferencia, sendo necessário que nos perguntemos sempre de qual mulher estamos falando, quando nos referimos à perspectiva feminista. Neste sentido, sugiro o texto: "Enegrecer o feminismo: a situação da mulher negra na América Latina a partir de uma perspectiva de gênero", de Sueli Carneiro (2011, s/p), quando a autora afirma que "[...] a luta das mulheres negras contra a opressão de gênero e de raça vem desenhando novos contornos para a ação política 
Zeca ainda está entre nós e Carolina nos deixou em 1977, mas as duas permanecem muitíssimo "vivas". Se suas histórias pessoais se diferenciam, e há especificidades em suas identidades; ainda assim vários fios parecem aproximar estas duas mulheres; duas escritoras mineiras que por meio de seus escritos se fazem cruciais nos embates travados cotidianamente contra o machismo, a misoginia, o racismo, a intolerância e tantos outros ódios e opressões. Registraram realidades que necessitam ser transformadas com pautas que precisam ser revistas e fortalecidas.

É como o apelo feito por Gayatri Spivak (2010, p. 18), em especial à mulher intelectual: "a ela caberá a tarefa de criar espaços e condições de autorrepresentação e de questionar os limites representacionais, bem como seu próprio lugar de enunciação e sua cumplicidade no trabalho intelectual". Acredito que de seus diferentes lugares, Zeca e Carolina criaram e continuam a criar espaços, reflexões, representações.

O procedimento metodológico adotado foi uma pesquisa bibliográfica, sendo, portanto, levantados dados coletados em consultas a bibliografias, artigos científicos e notícias na internet. Entre a Introdução e a Conclusão, o texto apresenta duas partes: a primeira denominada "Intelectuais negras: autoras e autoridades de suas próprias histórias", versa sobre a representação social da mulher na sociedade, indo de "objeto" a sujeito. O propósito foi discorrer sobre intelectuais negras, usando as mesmas como suporte teórico para enunciar a importância de (re)conhecê-las também enquanto produtoras de conhecimento; sujeitas radicais que necessitam se autorrepresentar e partilhar o que produzem. Já na segunda parte intitulada: "A preta Carolina, que de tão alto grito feriu ouvidos", trato especificamente de Carolina Maria de Jesus, abordando um pouco de sua trajetória, apresentando suas con-

\footnotetext{
feminista e anti-racista, enriquecendo tanto a discussão da questão racial, como a questão de gênero na sociedade brasileira. Esse novo olhar feminista e anti-racista, ao integrar em si tanto as tradições de luta do movimento negro como a tradição de luta do movimento de mulheres, afirma essa nova identidade política decorrente da condição específica do ser mulher negra". No mesmo sentido, destaco ainda as argumentações da escritora Djamila Ribeiro (2019, p. 51) quando a mesma ressalta: "o não reconhecimento de que partimos de lugares diferentes, posto que experenciamos gênero de modo diferente, leva a legitimação de um discurso excludente, pois não visibiliza ouras formas de ser mulher no mundo".
} 
tribuições enquanto uma intelectual negra. A partir de suas narrativas de dor, sensibilidade e enfrentamento esse tópico teve como pretensão demonstrar a importância de Carolina enquanto escritora e mulher preta, que descreveu a si mesma, revelou problemáticas e abriu caminho para que demais histórias e realidades fossem apresentadas e resgatadas.

\section{INTELECTUAIS NEGRAS: AUTORAS E AUTORIDADES DE SUAS PRÓPRIAS HISTÓRIAS}

Nós mulheres negras já vivenciamos por séculos um "lugar" diferenciado na dinâmica social: subalterno e abjeto. Corpos ao mesmo tempo desumanizados, servis, mas também exóticos ou super sexualizados. É inegável que a história das mulheres negras no Brasil traz marcas em seus corpos. "Marcas de papéis sociais que não as veem como um corpo marcado pelo gênero feminino, mas, como instrumento de trabalho, ou um corpo suscetível à satisfação sexual dos antigos ou novos senhores" (MÁRCIA TOKITA, 2013, p. 124).

Quando falamos de representação social de corpos negros femininos é crucial antes de qualquer coisa, que entendamos que a luta pelo reconhecimento como mulher tem sido a batalha diária de milhares de mulheres negras nesse país. Embora contemos com muitos avanços, ainda temos um longo caminho a percorrer para garantir espaços de respeitabilidade e equidade para estas mulheres. Mas afinal, qual é a representação que recebem essas mulheres, se nunca se encaixaram como sexo frágil? A da negra subserviente seja por seus atributos domésticos ou físicos, vistos sempre como sedutores e disponíveis. Nota-se que essa representação enuncia uma mulher sempre disposta a servir, destaca-se em primeiro lugar a figura da mãe preta (mulher negra que cuida com seus dotes domésticos e culinários da família colonial), e que na atualidade reconfigura-se no papel das empregadas domésticas. Em um país composto em sua maioria por mulheres negras é reveladora a baixa representatividade destas em eventos, coleções, propagandas ligadas ao cosmético ou vestuários, por exemplo. Chama atenção um completo silenciamento sobre esta questão por parte dos meios de comunicação, e por outro lado iniciativas por parte dos mesmos que reforçam os papéis anteriormente citados. No entanto, não há dúvidas, 
"de que há um forte descontentamento de parte significativa de muIheres negras que recusam essa representação estereotipada e exige retratação" [...] (DAYANE ASSIS, 2017, p. 130-31).

A objetificação da mulher ainda hoje é uma representação que habitualmente encontramos nos meios de comunicação, o papel de empregada ou de alguém que possui somente atributos físicos e a tão referida "cor do pecado", permanecendo este como sendo o retrato da mulher negra brasileira. Em contraposição a essa representação nefasta e uma tentativa de aniquilação da identidade dessas mulheres, vemos inúmeros projetos para a autovalorização da mulher negra, "vale destacar as iniciativas voltadas a valorização das questões estéticas como o uso do cabelo natural, roupas e acessórios pertencentes à cultura afro, em suma busca-se um retorno ao encontro da mulher negra como ela é" (DAYANE ASSIS, 2017, p. 131).

A escritora negra norte-americana bell hooks ${ }^{3}(2019)$ ressalta que a pedagogia crítica, o compartilhamento de informações e o conhecimento entre mulheres negras são fundamentais para o desenvolvimento da subjetividade radical da mulher negra (não que as mulheres negras só possam aprender umas com as outras, mas porque as circunstâncias do racismo, do sexismo e da exploração de classe asseguram que outros grupos não necessariamente tenham interesse por incentivar nossa autodefinição).

Assim, esse processo demanda de nós uma grande honestidade com relação a como vivemos. Mulheres negras, em especial as estudantes, que estão buscando respostas sobre a formação social da identidade desejam saber sobre as nossas formas de ser. Quando compartilhamos de boa vontade nossa experiência pessoal com alguém, garantimos que uma pessoa não seja transformada em um ícone santificado. Quando mulheres negras aprendem sobre a minha vida, também aprendem sobre os meus erros, minhas contradições. Passam a saber tanto sobre as limitações quanto as forças que possuo, não podendo, portanto, me desumanizar me pondo num pedestal. Ao compartilhar as contradições

No texto o nome da intelectual negra norte-americana, bell hooks, está assim escrito, porque esta é uma solicitação da própria autora. "A escolha da letra minúscula é justificada pelo interesse da autora em dar mais enfoque ao conteúdo desenvolvido em suas obras e menos a sua pessoa" (PEDRO BORGES, 2019, s/p). 
em nossas vidas, ajudamos umas às outras a aprender a como lidar com elas "como parte do processo de se tornar uma pensadora crítica, uma sujeita radical” (bell hooks, 2019, p. 121).

Diante desta escolha em ser sujeita radical, bell hooks (1995) em seu texto chamado "Intelectuais Negras", faz um relato relevante no que diz respeito ao trabalho intelectual, principalmente quando se refere a grupos marginalizados, destacando o quanto esta é uma atividade útil. Sobre sua própria experiência ela descreve que foi ferida, desde a infância, às vezes perseguida e vítima de abusos, tendo encontrado na vida intelectual um refúgio, um abrigo onde podia experimentar uma sensação de atuar sobre as coisas e com isso construir sua identidade subjetiva. Reconhecendo que o pensamento crítico podia ser usado para sobrevivência, como podia ser uma força curativa na luta para combater o desespero da infância, a autora (como ela mesma declara), se tornou um eu autônomo na família disfuncional, levando-a a valorizar o trabalho intelectual. Valorizava-o não por ter trazido a ela status ou reconhecimento, mas porque apresentava recursos para intensificar a sobrevivência e prazer de viver. Ao mesmo tempo não pensava jamais no trabalho intelectual de algum modo divorciado da política do cotidiano, tendo optado conscientemente por tornar-se uma intelectual, uma vez que era esse trabalho que lhe permitia entender sua própria realidade e o mundo em volta, encarar e compreender o concreto (bell hooks, 1995, p. 466).

Este mesmo entendimento parece ter Grada Kilomba (2019, p. 28) quando nos diz: "enquanto escrevo, eu me torno a narradora e a escritora da minha própria realidade, a autora e a autoridade na minha própria história. Neste sentido, eu me torno a oposição absoluta do que o projeto colonial predeterminou"; ou ainda Joice Berth (2019, p. 45) quando esta destaca a necessidade de darmos "voz a pensamentos específicos de intelectuais que se formam dentro dos grupos diretamente atingidos", para que tenhamos a dimensão exata de quais ações de fato desencadeiam mudanças.

Essa experiência forneceu a base de minha compreensão de que a vida intelectual não precisa levar-nos a separar-nos da comunidade [...]. Confirmou desde o início o que líderes negros do século XIX 
bem sabiam - o trabalho intelectual é uma parte necessária da luta pela libertação fundamental para os esforços de todas as pessoas oprimidas e/ou exploradas que passariam de objeto a sujeito que descolonizariam e libertariam suas mentes (bell hooks, 1995, p. 466).

Este processo do qual comenta bell hooks (2019), enfrentado por ela, parece também ter ocorrido com muitas mulheres que dão suporte teórico a este texto: enfrentamentos, dores, escolhas, dedicação, empoderamento, no sentido do que Joice Berth (2019) evidencia. A autora argumenta que empoderar "seria estimular, em algum nível, a autoaceitação de características culturais e estéticas herdadas pela ancestralidade que lhe é inerente para que possa", devidamente abastecida(o) de informações e novas percepções críticas sobre si mesma(o) e sobre o mundo à sua volta e mais, munida(o) de suas habilidades e características próprias, construir ou descobrir em si mesma(o) instrumentos ou poderes de atuação no contexto em que vive e em prol da coletividade (JOICE BERTH, 2019, p. 21).

[...] aprender sobre essas mulheres que ousaram afirmar suas subjetividades radicais é parte da autorrealização da mulher negra. Atingir o poder, a identidade, a subjetividade radical não pode acontecer no isolamento. Mulheres negras precisam estudar as obras, críticas e autobiográficas, daquelas mulheres que desenvolveram seu potencial e escolheram ser sujeitas radicais (bell hooks, 2019, p. 121).

Entendo que é exatamente assim que atuou Carolina Maria de Jesus, mesmo que em seu tempo nem sequer tenha escutado a palavra empoderamento, foi uma revolucionária (de dentro para fora), atuante em batalhas diárias. E é com a disposição de me unir às ideias de bell hooks (1995, p. 466-67) que ressalto seus dizeres: "apesar do testemunho histórico ${ }^{4}$ de que as negras sempre desempenharam um papel importante como professoras pensadoras críticas e teóricas culturais na vida negra em particular, nas comunidades negras segregadas", é

4 Desde o sequestro na África até sua chegada e tempo de permanência no Brasil, as mulheres negras sempre exerceram espaços de resistência. Foram inúmeras formas, como por exemplo, as fugas e formação de quilombos, onde viviam de modo semelhante ao tempo em que estavam na África (MÁRCIA TOKITA, 2013, p. 125). 
notório que muito pouco se escreveu sobre intelectuais negras; o que ocorre é que quando a maioria dos negros pensa em grandes mentes quase sempre recorre a imagens masculinas. Façamos diferente!

\section{A PRETA CAROLINA, QUE DE TÃO ALTO GRITO FERIU OUVIDOS}

Carolina Maria de Jesus é uma importante personagem negra de e da história 5 deste país. Ela foi uma mulher negra, migrante, saída da cidade de Sacramento no Triângulo Mineiro, Estado de Minas Gerais, no ano de 1947. Era mãe solteira e foi moradora da primeira grande favela da cidade de São Paulo [Canindé]. Carolina somente emergiu do anonimato absoluto por iniciativa de um jovem e brilhante jornalista, chamado Audálio Dantas ${ }^{6}$, que, vivenciando uma fase da cultura de comunicação de massas no Brasil, expunha ao público o jornalismo de denúncia. É interessante notar que nessa época a sociedade brasileira passava por uma rica experiência democrática. Portanto, é no período que vai entre a superação do Estado Novo (1937-45) e a instalação da Ditadura Militar (1964) que se coloca a experiência de Carolina Maria de Jesus refinada em sua primeira publicação: Quarto de Despejo: diário de uma favelada (JOSÉ MEIHY, 1998).

Carolina saiu de Minas Gerais por conta da miséria absoluta que devastava seu meio social de camponeses despossuídos. Filha de negros "retintos" ela peregrinou pelo interior do seu estado assumindo profissões variadas que iam de empregada doméstica a artista de circo. Perambulou até chegar aos limites da capital paulista onde trabalhou em algumas casas de famílias. Incompatibilizada com as regras de trabalho nestas casas, Carolina quis alçar vôos próprios e passou a ser catadora de papel. Supõe-se que naquele tempo o "negócio" de catadora(o) era algo mais rentável do que seria hoje. "Além do mais, com esse tipo de

5 Vale destacar a obra "Mulheres do Brasil: a história não contada", de Paulo Rezzutti (2018), onde o autor nos conta como mulheres negras, como Maria Felipa de Oliveira ou Almerinda Farias Gama, foram tornadas invisíveis, apagadas da história.

6 No referido contexto dos anos 60, os jornalistas adquiriam papéis importantes como documentadores das transformações nacionais. Audálio Dantas foi um dos primeiros profissionais a se notabilizarem nessa área, e a "descoberta" de Carolina pode ser vista como um de seus trunfos. Dantas se interessava pelas causas sociais, era também militante e ativista de esquerda (JOSÉ MEIHY, 1998, p. 86). 
trabalho, Carolina conseguiria tempo para seus afazeres domésticos como mãe e sobretudo como leitora e escritora que julgava ser" [e era] (JOSÉ MEIHY, 1998, p. 85).

Tendo sido, ainda em Sacramento, alfabetizada até o segundo ano primário, matriculada em uma instituição espírita, Carolina desde cedo, segundo o que ela própria afirmava, decidiu ser "artista" e isso para ela significava o avesso do mundo rural. Sua vocação nitidamente urbana a levava a somar a imperfeita alfabetização como habilidade para viver na cidade grande. "Mesmo na metrópole, em contexto de pobreza urbana quase absoluta, Carolina conseguiu se distinguir tanto por ser mulher bonita como por saber ler e escrever" (JOSÉ MEIHY, 1998, p. 85).

É interessante observar que a obra de Carolina representava para ela a forma de mediação com o mundo não marginal, pois considerava, em sua elaboração narrativa, a chance de saciar uma necessidade sócio-cultural e uma maneira de participar de outros territórios. Embora fale do universo da favela, Carolina escreve para registrar suas ideias e revelar à burguesia paulistana o que ocorre nesse ambiente "inhospito"7, como se quisesse provar a urgência do dever de se desfazer daquele lugar. O que, aliás, ela acreditava ser possível de ser realizado por meio do desenvolvimento capitalista e "suas possibilidades de trabalho" (RAFFAELLA FERNANDEZ, 2008, p.128).

E no foco do que me propus aqui, quais contribuições poderíamos dizer que trouxe Carolina Maria de Jesus para as mulheres negras, imersas numa sociedade que sempre as colocou em um plano inferior e discriminatório, ou invisibilizado? Penso ficar evidente uma importância primária em texto escrito por Audálio Dantas, chamado "Nossa irmã Carolina". Na apresentação o jornalista assim escreve: “eu vi e senti. Ninguém podia melhor do que a negra Carolina escrever histórias tão negras. Nem escritor transfigurador poderia arrancar tanta beleza triste daquela miséria toda"' (JOSÉ MEIHY, 2004, p. 27-28). Ou seja, Carolina falou do que a sociedade não queria falar, e de coisas e pessoas que não se queriam ver, escancarou de forma desbravadora histórias pre-

Esta palavra, assim como outras aqui citadas fazem parte do vocabulário de Carolina Maria de Jesus e estão presentes em sua obra, as quais procuramos respeitar em sua originalidade, ainda que fujam da norma culta da língua portuguesa. 
tas e a realidade miserável de negras e negros deste país. Mas, cabe destacar que sua obra também tem outras importantes nuances, como abordarei em seguida.

Michel Leandro (2019) ressalta que na década de 60, Carolina torna-se a autora mais vendida do país, através de uma escrita de enfrentamento social, "não sem contradições, a partir de um enredo do "lixo", daquilo que ninguém queria ver e "inaugura" a visibilidade da escrita literária de autoria de mulheres negras periféricas".

Para Raffaella Fernandez (2008) uma dessas contradições apresentada em Quarto de despejo, fica evidente com a presença de uma visão conflituosa do ser negro (que ainda persegue muitas(os) de nós).

Na primeira citação, a narradora-protagonista valoriza sua condição de mulher negra, inclusive negando-se a partilhar do universo do ser branco. Na segunda passagem, a protagonista associa a miséria material ao ser negro, associando a cor preta da favela e de sua pele à pobreza, tristeza, ao feio e ao sujo. Aqui temos mais um exemplo do que vem a ser a reprodução da estrutura de poder da sociedade. Ao entrar em embate com o ser branco, a personagem ativa um discurso que lhe permite se defender do menosprezo de que é alvo, mas quando imerge em sua solidão, a mesma trai seu discurso e posiciona-se como portadora de um símbolo cuja representação é uma imagem de isolamento/desolamento (RAFFAELLA FERNANDEZ, 2008, p.138).

De fato, conflitos e paradoxos vez ou outra aparecem, quando, por exemplo, Carolina de Jesus (2014b, p. 22) escreve: "tem hora que revolto-me. Depois domino-me". Ou quando descreve dois contrapontos da favela: a facilidade com que os boatos circulam e a solidariedade: "em poucos minutos o boato circulou [...]. E pensei na eficiência da lingua humana para transmitir uma noticia”. E logo depois diz: “já habituei beber café na casa de Seu Lino. Tudo que eu peço a eles emprestado, eles empresta. Quando vou pagar, não recebem" (CAROLINA DE JESUS, 2014b, p. 24).

No tempo e no "quarto de despejo" em que vivia Carolina, me parece extremamente revolucionária sua experiência: de sensibilidade e melancolia; ao mesmo tempo irônica e reflexiva; realista e transgressora. Impressiona a mulher Carolina que chega ao inferno, mas ao mesmo 
tempo acorda alegre; se autovaloriza por sua índole e por não precisar de marido para se sustentar; e mesmo na labuta de buscar água diariamente é capaz de doar-se à contemplação de um céu estrelado. Carolina é mulher para se admirar: entendia da política e de ser política(o); refletia sobre a vida em que levava. E ela não desistia: de suas leituras, de sua escrita; nem com fome ou aborrecida; apesar da miséria ou de ter perdido o hábito de sorrir. Não se descuidava dos filhos, nem do seu trabalho. E no seu diário ao mesmo tempo em que lemos: "pobre não repousa” (CAROLINA DE JESUS, 2014b, p. 12), vemos também: “mas eu sou forte! Não deixo nada imprecionar-me profundamente. Não me abato" (CAROLINA DE JESUS, 2014b, p. 21).

Em Quarto de despejo descobrimos não apenas a linguagem da favela, mas também, formas de opressão e repressão, exclusão, as injustiças sociais, traços culturais do Brasil, equívocos de seu plano de "democracia". "Sua voz existe na contramão da história oficial. Sua experiência literária traz à luz comunidades de netos e bisnetos de ex-escravos, e de toda uma população brasileira pobre, que, fatalmente, contribui para essa literatura em desenraizamento" (RAFFAELLA FERNANDEZ, 2008, p.144).

O que se valoriza na reconstituição dos caminhos percorridos [por uma das mais importantes escritoras negras do Brasil] são os dilemas e as incoerências do nosso meio, refletidos na singularidade de uma vida. Por si só a biografia de Carolina Maria de Jesus valeria enquanto imagem de um tipo único, incomum e exuberante, "mas, muito mais do que isso, ela sintetiza a experiência da nossa cultura como um todo, submetida às ambivalências da opinião pública e do juízo histórico" (JOSÉ MEIHY, 2004, p. 39).

O escritor Tom Farias apud Marisa Loures (2019, s/p) afirma que Carolina foi "uma mulher extraordinária, uma escritora profunda e fantástica". Afirma que pôde aprofundar seus conhecimentos sobre ela a partir dos escritos que a mesma deixou; não somente pelos textos traduzidos em diários, mas os de ficção, embora menos conhecidos, e, sobretudo, nos de poesia, que ficaram menos famosos. Chama atenção ainda a Carolina militante política com o viés feminista/feminino, amante da reforma agrária e do fim das favelas: ela foi uma voz potente no 
campo da denúncia social e racial, situando, sem receio, sua presença na cena brasileira, especialmente nos anos 60." [...]. Em 1960, Carolina completava 20 anos de vida literária, estreada em jornal em 1940; lutava contra a fome e também por um lugar ao sol da literatura. "E mais, ela tinha consciência da sua realidade, tinha noção do preconceito racial que moviam contra ela, mas também tinha conhecimento que estava acima da média nacional do nível intelectual das mulheres em geral, e das mulheres brancas" (TOM FARIAS apud MARISA LOURES, 2019, s/p).

É bastante relevante não só a vivência desta escritora, mas sua noção de mundo, mesmo em meio a um contexto tão adverso. Carolina Maria de Jesus (2014b, p. 21) fascina quando relata em seu diário: "deixei o leito as 4 horas para escrever"; ou "enquanto as roupas corava eu sentei na calçada para escrever" (CAROLINA DE JESUS, 2014b, p. 23). Ou ainda quando ela argumenta: "então o mundo já foi pior para os negros? Então o mundo é negro para o negro e branco para o branco!” (CAROLINA DE JESUS, 2014a, p. 59).

Neste sentido Michel Leandro (2019, p. 127) ressalta que Carolina produz uma literatura de enfrentamento social, uma vez que materializa uma escritura que estabelece o seu projeto literário neste lugar da ruptura, do não-lugar, do impensado, a partir da produção de novos sentidos, em direção da denúncia social das adversidades de um país que se quer "debaixo do tapete", diríamos, silenciado, cuja visão não é "cheirosa”, muito menos agradável. Ainda que por uma ótica pessoal, os escritos de Carolina trazem problemáticas que transcendem a esfera do individual.

Ser negra num mundo dominado por brancos, ser mulher num espaço regido por homens, não conseguir fixar-se como pessoa de posses num território em que administrar o dinheiro é mais difícil do que ganhá-lo, publicar livros num ambiente intelectual de modelo refinado, tudo isto reunido fez da experiência de Carolina um turbilhão (JOSÉ MEIHY; ROBERT LEVINE, 1994, p. 63 apud MARÍLIA MACHADO, 2006, p. 108).

A autora Carolina, às vezes de forma deliberada, outras vezes por suas próprias intenções, infringiu os códigos que sustentavam a 
imobilidade, perenidade e reprodução da desigualdade social no país, gerando, assim, outras significações imaginárias sociais. Ela sofreu as consequências do rompimento com a continuidade. Não por coincidência foi chamada de difícil, rebelde, petulante, geniosa, atrevida, transgressora, ousada, explosiva, violenta, arrogante. Assim que seu sucesso entrou em declínio, chamaram-na de: fracassada, vítima e louca. "Mas chamaram-na também de terna, alegre e corajosa" (MARÍLIA MACHADO, 2006, p. 105). Para bell hooks (2019, p. 118) "sujeitas negras radicais são constantemente rotuladas como loucas por aqueles que desejam minar seu poder pessoal e sua habilidade de influenciar os outros".

Michel Leandro (2019, p. 94) destaca que no caso de Carolina, sua primeira ${ }^{8}$ obra Quarto de despejo, só é o que é: famosa e vendável, porque foi lida por muitos [e muitas] não como literatura, mas como relatos verídicos de alguém, conectados à ilusão de transparência da linguagem, desta forma, importa a obra, porque antes de tudo existe o interesse por quem escreveu, sujeito-exótico, voz de quem estava dentro da favela e não fora, tanto é que outras obras ${ }^{9}$ e histórias da autora não alcançaram a mesma popularidade, já que o público leitor se interessa(va) pela escritora apenas na posição de "A Favelada".

Neste sentido o preconceito linguístico sofrido por Carolina, vai além da questão social e estética. "É o caráter do grupo político e econômico dominante no Brasil. De mais a mais, Carolina está sendo estudada, não aceita". Destaca ainda que nos dias atuais gênero e ancestralidade dizem muito desse lugar de fala que a sociedade reivindica. Sendo uma voz potente, que protesta com relação ao seu lugar na sociedade, o incômodo Carolina continua intimidando mesmo os que a leem com os olhos da atualidade. Ou seja, o grito por justiça social de Carolina continua vivo, enquanto as injustiças sociais continuam constantes, seja na

8 Cabe ressaltar o que diz o jornalista e escritor Tom Farias, autor da obra "Carolina: uma biografia", publicada pela Editora Malê (2017). Em entrevista concedida a Marisa Loures (2019), publicada na Tribuna de Minas, ele afirma: "diferentemente do que muitos sabem, muitos anos antes de "Quarto de despejo", ela já escrevia”.

9 As outras obras da autora são: Casa de alvenaria (diário, 1961); Provérbios (memória, 1963); Pedaços da fome (memória, 1963); Diário de Bitita (memória, 1986); Antologia pessoal (poemas, 1996); Meu estranho diário (1996). Estas informações foram retiradas do livro Quarto de despejo, de Carolina de Jesus (2014b, p. 199). 
alta proporção do preconceito de raça e classe, seja no extermínio da população negra, sobretudo os jovens, seja no feminicídio (que alveja de forma violenta, a maioria das mulheres negras) (TOM FARIAS apud MARISA LOURES, 2019, s/p). É como disse Carolina Maria de Jesus (2014, p. 58) em seu "Diário de Bitita": "apenas sorriam achando graça de ver os negros correndo de um lado para o outro [e continuam a correr]. Procurando um refúgio, para não serem atingidos por uma bala".

Algo que moveu a vida de miséria de Carolina foi acreditar sempre que poderia ter tudo mudado através da sua literatura. [...] O desespero e o desamparo levaram Carolina a acreditar na única ferramenta disponível para transformar revolucionariamente a realidade de sua vida: a escrita. Afinal, Carolina está hoje em 16 idiomas e 46 países. Foi best-seller em 11. São milhares de livros vendidos em todo o mundo. Que mulher preta alcançou tudo isso apenas com o talento? Conceição Evaristo, somente aos 70 anos, vem conquistando a glória. Carolina se arrojou para que uma Conceição surgisse, assim como Conceição vem abrindo caminhos para outras mulheres negras escritoras. A glória é um bom estímulo para a criação; já a glorificação é traiçoeira. Carolina de Jesus esteve nas mãos de uma e de outra (TOM FARIAS apud MARISA LOURES, 2019, s/p).

Assim, espaços são criados para que outras escritoras, cuja escrita é atravessada pela condição interseccional de mulher negra, sejam reconhecidas. Cabe, ainda, destacar que essa escrita não está sempre associada a questões feministas e femininas, pois essas mulheres são, antes de tudo, escritoras de literatura e a literatura não se limita e nem aceita "caixas", contrariamente, ela serve para rompê-las e transcendê-las. "Logo, a escrita das mulheres negras, além de reafirmar identidades, vem romper com os padrões que as marginalizam e as subalternizam" (DÊNIS QUADROS, 2018, p. 244).

Embora as histórias da literatura neguem espaço à escritora Carolina de Jesus, seu nome persiste na Academia, cujas pesquisas não param, e a cada nova só fortalece a rede que as outras estabeleceram. Carolina é sim a "voz" que ecoa das favelas, a mulher negra que teve a coragem de criticar o governo, de refletir sobre diversos temas, poeta que não se calou perante a monstruosa condição. Como precursora da literatura 
afro-feminina brasileira, Carolina "abre espaço para legitimarmos outras como Maria Firmina dos Reis (122-1917), Zeli de Oliveira Barbosa (19412017), Mel Adún (1978-), Conceição Evaristo (1946-), Cristiane Sobral (1974-), Mel Duarte (1989-) e muitas outras resgatadas e ainda atuantes" (DÊNIS QUADROS, 2018, p. 253-54). Ousei falar sobre Carolina Maria de Jesus, de escrita e voz vigorosa, mas poderia ser sobre muitas outras; todas elas resgataram a si mesmas e resgatam todas nós.

Carolina descansou deste mundo, já não está mais entre nós, digo em materialidade, morreu no século passado; seu corpo físico não passeia mais por aqui, porém suas ideias dançam, seguem repercutindo; "a morte não foi o ponto final da escritora” (MARÍLIA MACHADO, 2006, p. 108). É “"Carolina, você gritou tão alto que o grito terminou ferindo ouvidos"” (JOSÉ MEIHY, 2004, p. 28). Feriu os meus! Afetou-os de tal maneira que trouxe à tona dores, desalentos, rebeldia, mas ao mesmo tempo acolhida e poesia. E uma certeza: a de que não podemos desistir.

\section{CONCLUSÕES E (RE)COMEÇOS}

Por estes escritos sinto-me honrada em ter tido a chance de homenagear a Zeca, não só para engrandecê-la, mas para também agradecê-la, por ter sido sempre uma mulher inspiradora, acessível, aberta ao diálogo, generosa na e para a partilha, intelectual, subversiva, altamente gentil, mas ao mesmo tempo firme, quando necessário. Agradeço por ter sido sua orientanda, pela confiança, por nosso encontro, por ter aprendido muito, por ter sido como foi.

E de forma análoga engrandeço as mulheres pretas, por Carolina Maria de Jesus. Agradeço a todas que vieram antes de mim, pelas que ainda estão aqui e pelas que virão, e que tecerão os mesmos fios, mesmo que com cores e jeitos diversos. É por conta delas que hoje estou aqui e posso falar: de Zeca, Carolina e de mim. Porque um dia tudo foi silêncio, e o silêncio ainda persiste, em muitos lugares e em muitas muIheres pretas. Mas também há vozes que por anos não foram ouvidas, mas que insistem em reverberar; há vozes que não querem mais serem silenciadas, que clamam, acolhem e que transformam. Não somos objetos, mas sujeitos. Não descrevi Carolina. Ela descreveu a si mesma. Essas mulheres pretas presentes neste texto, falam por si só, mas elas 
também falam em meu nome, e o que elas falam também é sobre mim; eu falo delas, e tudo que falamos é sobre muitas outras.

Zeca e Carolina embora falem de lugares diferenciados, também se encontram em suas buscas e reivindicações, as duas perseguiram o que acreditavam, apresentando demandas e direitos que almejavam fossem (re)considerados. Criam pontos de interseção quando influenciam e inspiram outras mulheres, ou quando as entendem como sujeitos sociais, cidadãs, "com o direito de interferir na esfera política da sociedade" (MARIA ROSADO-NUNES, 2008, p. 78). Carolina parecia entender bem o que Maria Rosado-Nunes (1994) apud Maria Rosado-Nunes (2008) quer dizer ao afirmar: [...] a mulher também tem que se doar para si mesma, tem que pensar nela.

Ao fim deste trabalho, não da luta, é possível algumas considerações ou conclusões, como preferem algumas/alguns: Carolina, embora muitas vezes rechaçada, é uma intelectual negra, dentre muitas outras, uma escritora que de seu quarto de despejo sonhou passar ao quarto de alvenaria a partir daquilo que ela mais valorizava: suas leituras e sua escrita. Embora merecesse mais ao final de sua vida, os espaços e questões por ela levantadas seguem ecoando, seu grito continua ferindo ouvidos, por todo tipo de incômodo que ele provocou ou que ainda pode provocar.

Desta maneira há muitas intelectuais negras, com potentes produções, embora nem sempre reconhecidas socialmente. Porém, é crucial a continuidade deste trabalho intelectual, pois ele é parte da luta pela emancipação destas mulheres. É primordial que entre nós façamos a partilha deste conhecimento produzido, sendo fundamental ainda que nas pautas feministas, mulheres brancas não ignorem suas responsabilidades para uma mudança de fato significativa. E há muita mudança a ser feita; pois como dizia Carolina de Jesus (2014a, p. 155): “[...]Temos que despertar. O país não pode continuar deitado eternamente em berço esplêndido. [...]".

Sinto-me assim, transformada, ou melhor, em transformação, guiada por essas mulheres, protagonistas de suas próprias histórias: Zeca e Carolina; e por tantas outras sujeitas radicais que me afetam profundamente. Sigo com algumas conclusões, mas disposta a (re)começos. 


\section{REFERÊNCIAS}

ASSIS, Dayane Nayara Conceição de. Corpos negros e representação social no Brasil: uma discussão de gênero e raça. Revista da ABPN, volume 9, n.21, pp.123-134, 2017.

Disponível em: <http://abpnrevista.org.br/revista/index.php/revistaabpn1/article/view/231>. Acesso em: 02 jun. 2020.

BERTH, Joice. Empoderamento. São Paulo: Selo Sueli Carneiro, Pólen, 2019. BORGES, Pedro. Editora lança livro de bell hooks sobre racismo em São Paulo.

Alma Preta, Jornalismo Preto e Livre. 2019. Disponível em: < https://www.almapreta. com/editorias/realidade/editora-lanca-livro-de-bell-hooks-sobre-racismo-em-sao-paulo>. Acesso em: 13 jun. 2020.

CARNEIRO, Sueli. Enegrecer o feminismo: a situação da mulher negra na América Latina a partir de uma perspectiva de gênero. 2011. Disponível em: <https://www.geledes.org. br/enegrecer-o-feminismo-situacao-da-mulher-negra-na-america-latina-partir-de-uma-perspectiva-de-genero/>. Acesso em: 11 de maio 2020.

hooks, bell. Intelectuais negras. Estudos Feministas, volume 3, ed.2, pp. 464-478, 1995.

. Olhares negros: raça e representação. São Paulo: Elefante, 2019.

FERNANDEZ, Raffaella Andréa. Percursos de uma poética de resíduos na obra de Carolina Maria de Jesus. Itinerários, n.27, pp.125-146, 2008.

FREIRE, Paulo. Pedagogia do oprimido. $13^{\text {a }}$ edição. Rio de Janeiro: Paz e Terra, 1987. JESUS, Carolina Maria de. Diário de Bitita. São Paulo: SESI-SP editora, $2014 a$.

. Quarto de despejo: diário de uma favelada. 10 edição. São Paulo: Ática, 2014b. KILOMBA, Grada. Memórias da plantação: episódios de racismo cotidiano. $1^{a}$ edição. Rio de janeiro: Cobogó, 2019.

LEANDRO, Michel Luís da Cruz Ramos. Autoria e resistência: Carolina Maria de Jesus em discurso. 184p. Dissertação (Mestrado) - Faculdade de Filosofia, Ciências e Letras de Ribeirão Preto/USP, Ribeirão Preto, 2019.

LOURES, Marisa. Tom Farias: "Carolina ainda continua assombrando a sociedade brasileira”. Entrevista. Tribuna de Minas. 2019. Disponível em: <https://tribunademinas.com. br/blogs/sala-de-leitura/25-06-2019/tom-farias-carolina-ainda-continua-assombrando-a-sociedade-brasileira.html>. Acesso em: 29 jun. 2020.

MACHADO, Marília Novais da Mata. Os escritos de Carolina Maria de Jesus: determinações e imaginário. Psicologia \& Sociedade, volume 18, n.2, pp.105-110, 2006.

MEIHY, José Carlos Sebe Bom. Carolina Maria de Jesus: emblema do silêncio. Revista USP, n.37, pp.82 - 91, 1998.

. Os fios dos desafios: o retrato de Carolina Maria de Jesus no tempo presente. In: SILVA, Vagner Gonçalves da. (Org.). Artes do corpo. São Paulo: Selo Negro, 2004. 
QUADROS, Dênis Moura de. A escritora Carolina Maria de Jesus: legitimando seu lugar na história da literatura brasileira. Revista Travessia, volume 12, n.1, pp. 243 - 257, 2018. Disponível: <http://saber.unioeste.br/index.php/travessias/article/view/19198/12628> Acesso em: 25 maio 2020.

REZZUTTI, Paulo. Mulheres do Brasil: a história não contada. Rio de Janeiro: LeYa, 2018. ROSADO-NUNES, Maria José. Direitos, cidadania das mulheres e religião. Tempo social, São Paulo, volume 20, n. 2, pp. 67-81, 2008 . Disponível em: <http://www.scielo.br/ scielo.php?script=sci_arttext\&pid=S0103-20702008000200004\&lng=en\&nrm=iso >. Acesso em: 22 jun. 2020.

SPIVAK, Gayatri Chakravorty. Pode o subalterno falar? Belo Horizonte: Editora UFMG, 2010.

TOKITA, Márcia Figueiredo. Mulheres negras. In: Simpósio Internacional Lutas Sociais na América Latina - "Revoluções nas Américas: passado, presente e futuro", V, 2013, Londrina. Anais... pp.120-133.

Submetido em: 1-8-2020

Aceito em: 13-11-2020 